\title{
'I am walking - do I need an admission?': A new cauda equina syndrome integrated care pathway for ambulant patients
}

\author{
Authors: Verity Thakur, Manish Desai, Rosa Castro, Samantha Craddock and Vijay Kolli
}

\begin{abstract}
Aims
Background

Cauda equina syndrome (CES) is a potentially devastating event resulting in life-changing long-term neurological disability. This may be visible disability such as impaired mobility, but will also involve invisible disability such as neuropathic pain, urogenital and bowel dysfunction, and psychological sequelae, alongside vocational and relationship issues.

\section{What are the national standards?}

> Patients with CES should be treated by specialist healthcare staff in spinal cord injury centres.

> Early rehabilitation is crucial and provides the best chance of optimal management of persisting deficits, coping with long-term impairment and returning to the highest level of functioning, even if the neurological recovery is incomplete.
\end{abstract}

What is the problem with usual management?

Traditionally, paraplegic CES patients are referred for inpatient rehabilitation, whereas ambulant CES patients are treated as outpatients. This requires multiple separate referrals and appointments, usually over at least a year, with the risk of fragmented care and being lost to follow up.

What have we done differently?

We introduced an innovative integrated care pathway (ICP) for ambulant CES patients, for a 3-week fast-track inpatient rehabilitation programme. We are the first centre in the country to implement this.

\section{Aims of this study}

To examine the effectiveness of the pathway, benefits to patients, and outcomes of rehabilitation.

Authors: London Spinal Cord Injury Centre, Royal National Orthopaedic Hospital, London, UK

\section{Methods}

A 12-month prospective analysis of ambulant CES ICP admissions.

\section{Results}

Over 12 months, there were 19 admissions (41\% female, 59\% male, age range $18-65)$. The most common aetiology was disc prolapse $(63 \%)$ followed by trauma or infection $(11 \%$ each). Most patients had issues around spinal injury education, bladder and bowel management, and psychological impact addressed during their admission (see Table 1). However, only around a third accessed the sexual function nurse specialist. The rehabilitation outcomes in terms of bladder and bowel management showed that all patients achieved safe and effective control (see Table 2).

\section{Table 1. Percentage of ambulant cauda equina} syndrome patients achieving the rehabilitation objectives within the admission

\begin{tabular}{|c|c|}
\hline Admission objective & $\begin{array}{l}\text { Ambulant CES } \\
\text { patients for } \\
\text { whom this was } \\
\text { achieved during } \\
\text { the admission }\end{array}$ \\
\hline Completed spinal injury education programme & $89 \%$ \\
\hline $\begin{array}{l}\text { Neuro-urology review and ongoing plan } \\
\text { made }\end{array}$ & $89 \%$ \\
\hline Bladder investigations completed & $79 \%$ \\
\hline $\begin{array}{l}\text { Formal meeting to discuss diagnosis and } \\
\text { prognosis with a rehabilitation consultant }\end{array}$ & $63 \%$ \\
\hline $\begin{array}{l}\text { Bowel specialist nurse review and ongoing } \\
\text { plan made }\end{array}$ & $100 \%$ \\
\hline Sexual function specialist nurse & $39 \%$ \\
\hline $\begin{array}{l}\text { Psychology review and counselling, with } \\
\text { ongoing follow-up plan }\end{array}$ & $79 \%$ \\
\hline Orthotist review & $74 \%$ \\
\hline
\end{tabular}




$\begin{aligned} & \text { Table 2. Rehabilitation outcomes for bladder and } \\
& \text { bowel management }\end{aligned}$
\begin{tabular}{lll}
\hline Rehabilitation outcome & $\begin{array}{l}\% \text { of } \\
\text { ambulant } \\
\text { CES ICP } \\
\text { patients }\end{array}$ \\
Bladder management & Urge voiding & $24 \%$ \\
& Intermittent self- & $71 \%$ \\
& catheterisation & \\
& Indwelling catheter & $5 \%$ \\
& Incontinent or needing pads & $0 \%$ \\
Bowel management & Opening on urge & $32 \%$ \\
& Digital removal of faeces & $47 \%$ \\
& Anal irrigation system & $21 \%$ \\
& Incontinent or needing pads & $0 \%$ \\
\hline CES = cauda equina syndrome; ICP = integrated care pathway.
\end{tabular}

\section{Conclusion}

Areas for improvement

We need to ensure all patients have a formal meeting to discuss diagnosis and prognosis, and we need to improve access to the sexual function specialist nurse. A further study may include functional spinal cord injury outcome measures and patientreported quality of life scores in a retrospective direct comparative study with outpatient care.

\section{Take-home message}

The CES ICP is an innovative, holistic, inpatient rehabilitation programme with structured goals around patient education and self-management. This is particularly important for getting ambulant CES patients with invisible disability back on track.

\section{Conflict of interest statement}

None declared. 